\title{
Globalisation and reflexivity:
}

some challenges for research into quality education mediated by ICTs

\author{
Terry Evans \\ Deakin University, Australia
}

\begin{abstract}
Globalisation can be characterised, Giddens (1994) suggests, as a process of 'intensified reflexivity' that creates the conditions for 'a world of clever people'. Information and Communication Technologies (ICTs) are fundamental to globalisation and they have also been incorporated into the new educational technologies deployed by educators to (re)create 'a world of clever people'. Together, education and the ICTs are strong forces for globalisation where both curriculum and pedagogy shape the knowledge and values of the rising generation of 'clever people'. This chapter posits some research issues and questions that might be usefully pursued in transnational collaborative research or are germane to its conduct and contexts. These matters include: the place of ICTs in research work; the challenge of globally inclusive curricula and the impact of English as the global language; and ICTs decentring the research centre
\end{abstract}

Key words: globalisation research educational technology

\section{INTRODUCTION}

This paper has its origins in two international conferences that I attended in 2002: one in Brazil, where some of the first words of this text were formed; and the other in Thailand, where some further revisions and extensions were made. It had its conclusion in a keynote presentation at the IFIP conference in Australia. I would like to reflect briefly on the contexts of these international conferences as an introduction into the substance of the paper because I think these contexts are illustrative of the contradictions and challenges we face in developing and providing quality education at a distance.

The first conference (on distance education) was organised by UniRede (Universidade Virtual Pública do Brasil) and two other distance education

The original version of this chapter was revised: The copyright line was incorrect. This has been corrected. The Erratum to this chapter is available at DOI: 10.1007/978-0-387-35700-3_33 
organizations (CEDERJ and AIESD). UniRede is a new, emerging organization of about 60 Brazilian public universities. UniRede is committed to enabling public universities (of which there are about 95 in Brazil) to make the transition to distance education so that they can help the poor, and not so poor, become and remain well enough educated to participate in a society increasing affected by the knowledge economy and the information age. However, the economic circumstances of Brazil are difficult and concern is expressed that global capitalism is not working in the best interests of the nation; certainly not for the majority of the people.

I presented at this conference on two topics: undergraduate distance education in Australia; and distance education, technology, interaction and globalisation. There were some ironies for me in these experiences. One was that the purpose of the conference was to bring Brazilian public higher education into the $21^{\text {st }}$ Century in terms of its educational practices, particularly in terms of the use of ICTs: that is, the same ICTs that are the lifeblood of global capitalism. Another was that the keynote speakers included an Argentine, an Australian (me) and a Briton, as well as two Brazilians. The conference was in Portuguese, the language of Brazil. The Argentine presented in Spanish and it appeared all delegates (except the Australian and the Briton) either knew Spanish well enough or could rely on the similarities between their two languages to comprehend the gist of the argument. The Australian and the Briton spoke in English (their only language)-with simultaneous translation being undertaken into Portuguese-to Powerpoint slides in Portuguese. The Brazilians spoke in Portuguese with simultaneous translations into English for the Australian and the Briton. Hence, it seems ironic that globalisation may well be operating effectively in the world of finance and business but, when we come to deal with its educational consequences, we have to work hard to be understood locally. It may also have been ironic that the two Anglophone monolinguists had their considerable linguistic strength in the de facto global language (see Crystal, 1997a, 1997b); the Portuguese monolinguists had their considerable strength in a language that provides few international communications, other than those with other ex-Portuguese colonies in Africa and Asia as well as with the ex-colonial power, Portugal.

In Thailand I also presented on two topics at a conference on educational technology and distance education. One, with Elizabeth Stacey, on flexible learning for quality in higher education and the other one as part of a panel with a senior Thai bureaucrat and a senior UNESCO manager. My panel topic concerned valuing the local in global partnerships. Unlike my Brazilian experience, this conference was in English, with no Thai translations of any kind. Also unlike Brazil, Thailand is one of the few developing nations in the world never to have been colonised by a European power. However, 
nowadays the 'neo' colonisation of global capitalism and American'inspired', Anglocentric culture is obviously prevalent to those who look and hear; especially when the topic or the medium is ICT-related. The conference actors said their (English) parts on the stage of an international high-class hotel, according to the dramatic structure of the Western academic conference, using their Powerpoint props, to/for/with an audience who knew their roles.

In terms of this chapter, my experiences of my first visit to Brazil and about my tenth visit to Thailand have helped me reflect critically on the matter of globalisation, ICTs and education, and particularly what this means for conducting and communicating research globally that might have an impact on what we see was quality education at a distance. It seems that this book on quality education at a distance is a context in which these matters may be particularly apposite. Of course, the IFIP conference which preceded the book had its own contradictions, not the least of which was being the conference of a European-centred organization being held in Australia, an ancient land over which many Aboriginal nations had custody, and which was colonised by the British in the $18^{\text {th }}$ Century. Of course, the language of the conference was both the official language of Australia imposed by the colonial masters and the de facto global language.

I shall commence with an explanation of my interpretation of globalisation and then bring the matter of ICTs and education into the discussion. From this position I identify some research issues that may be fruitful for consideration in the context of pursuing quality education at a distance in these ICT-connected days. Part of my interest here is to make the personal political, or maybe it is to make the intellectual critical. That is, I would like us to dwell on the some of the 'taken-for-granteds' that surround the moves into ICT-based 'global' education.

It is also important to declare that I view measures of quality as problematic. It seems that quality is essentially subjective and affective, and that attempts to measure its existence or gradations are damagingly reductionist. As Elizabeth Stacey and I have noted in a recent paper:

A good 'product' may be defined as one that is well-designed, welldeveloped and well-made and which on use and through evaluation and reflection is seen as fit for purpose/useful. However, to be a quality product - this seems crucial - it gives intrinsic pleasure to the users or those involved. (Evans \& Stacey, 2002, p.5)

Therefore, to consider the provision of quality education at a distance within multiple local contexts globally requires a recognition of the subject and affective concerns of the people in those local places. On this basis, it is necessary now to turn to consider these elements more fully. 


\section{GLOBALISATION, ICTS AND EDUCATION}

In the popular press and in everyday discussion the term 'globalisation' typically connotes international business and markets. Usually what is portrayed are the negative consequences of the practices of some 'global' corporations and also their support, or lack of control, by political and business leaders in the 'host' (invaded?) nation-states. The reduction of manufacturing in some developed nations and its relocation to developing nations with cheaper labour costs and fewer controls over companies' business, environmental, social and other activities are some of several (apparently inevitable) negative consequences of globalisation that are conveyed through the news media. Groups organised to resist these developments argue that globalisation is about the oppression of the world's poorest people and poorest nations, and the avaricious exploitation of them, their cultures and their natural environments, by greedy and powerful transnational corporations. It is not my intention to defend global capitalism or to downplay the consequences of the distortions of capitalist market economics, but I wish to argue that, conceptually, globalisation is more complex than this and is neither necessarily economic or capitalist in nature, nor inevitably bad for the world's population.

The real significance of globalisation for me rests in its social and cultural processes and consequences (Axford, 1995). A colleague, Daryl Nation, and I have argued (Evans \& Nation, 2001, p. 242) that:

...the origins of globalisation can be traced to the first endeavours of human societies to venture beyond their lands and shores to find and explore (and maybe, often to occupy, conquer and colonise) other places and peoples. The growth of transport and communications (and military) technology has aided the exploration and 'occupations' of the world. Not just in the relatively permanent sense of migration, but also in the sense of temporary incursions by business people, sportspeople, tourists and others. In their different ways they leave their 'footprints' on the local places, peoples and societies they visit. Each of these footprints can be seen as steps on the journey to what has been conceptualised as globalisation.

On this basis, globalisation can be seen to have its roots in the development of transport systems and communications going back centuries. However, it is the human imperative to explore (and conquer?) that is the driving force; without this imperative why bother to invent horseless carriages or telephones? We tend to think that the media and technologies drive us, without considering that it is (some of) us who yearn to develop them in the first place. 
The ICTs can be portrayed as another part of human invention and endeavour but, as with some other tools and technologies, they have produced more profound, even paradigmatic, changes to human experience and social life. The ICTs enable people to send and receive digital objects and data, and communicate with people and places, almost irrespective of where they are on the globe. I have explained elsewhere that:

(g)lobalisation implies that most people, if not all, are connected more or less contemporaneously with distant events, sometimes whether they like it or not. This 'time-space compression' (Giddens, 1994 , p. 7) is not just limited to communications and transport, but also to economic activity. The social and cultural implications...are intimately connected (Evans, 1997 p. 18).

The ownership of ICT infrastructure and of the means of access to the ICTs themselves, are distorted by the range of social, cultural and economic structures and processes that have created inequalities in the past. Therefore, in terms of broad participation in the ICTs, access is markedly better for the majority (but not all) the inhabitants of, for example, Amsterdam, London or Perth than it is for the majority of the inhabitants of, for example, Khon Kaen or Rio de Janeiro, let alone Addis Ababa or Khabul. This access itself is not just proscribed by a person's income or wealth, but also, using Bourdieu's (1971) concept, by their 'cultural capital'. Such cultural capital comprises the knowledge, skills, and English language capability to participate globally, to be a 'global citizen'. This has been expressed elsewhere as follows:

For someone to fly from Calcutta to Calgary requires not just the money for the ticket, but also the knowledge and skills to book the flights, obtain and use a passport and visa, check-in and board the flight, etc. To use the Internet to obtain information from those two cities requires a facility with language, not just any language, but almost invariably with the 'global language': English (Evans \& Nation, 2001, p. 242-243)

Clearly, in the context of understanding the future of ICTs in quality education (and business), the relationship between education and globalisation surfaces as one of importance. Other than the family, the main building sites of cultural capital are educational institutions, from schools through to universities: people have to learn to be equipped to be global citizens. This raises questions about the curricular and pedagogical places of ICTs in education (see, Cunningham and others, 1998, 2000), but also more broadly about other cultural capital building curricula, such as English, and those curricula that help people understand the people, places and systems outside of their local places, such as Geography and Environmental Studies, or History and Politics. 
Of particular relevance to the argument here is Giddens's work on the changing personal, social and political conditions encompassed by globalisation (Giddens, 1991a; 1991b;). Giddens uses the notion of 'timespace' compression to describe consequences of the new transport and communications systems. He argues that globalisation effects:

...the transformation of local, and even personal, contexts of social experience. Our day-to-day activities are increasingly influenced by events happening on the other side of the world. Conversely, local lifestyle habits have become globally consequential $(1994$, p. 5).

Giddens is pointing to what he calls the 'intensified reflexivity' of globalisation. Not only are people affected by events or decisions elsewhere, there is the sense in which a local is also an 'elsewhere' for others. The ICTs 'intensify' the reflexivity between locals, not as a bi-lateral relationship, but as an unbounded multi-lateral one: that is, globalisation. This indicates why it is important that people, en masse, are equipped/enabled to participate in this new global community. However, I would not want this to be interpreted as an argument for courses on 'computer studies' or 'IT studies', indeed such studies are probably largely irrelevant in this context beyond some basic understanding. Rather, as I have alluded to above, it is about understanding/teaching the knowledge, values and skills that enable communicative competence globally, hence, it is more about cross-cultural studies, than IT studies. It is Giddens who points to this when he argues that globalisation rests on 'a world of clever people'. For citizens to participate effectively and globally (and maybe even to learn within globalised/globalising forms of distance education), they need to learn curricula that enable them to deal with what might be called a 'worldly knowledge', rather than (just) local knowledge. Giddens suggests that,

... individuals more or less have to engage with the wider world if they are to survive in it. Information produced by specialists (including scientific knowledge) can no longer be wholly confined to specific groups, but becomes routinely interpreted and acted on by lay individuals in the course of everyday actions (1994, p. 7).

The implication here is that it is not just the 'time-space compression' that enables people to be interconnected to distant events and places, but also the access to a rapidly expanding, increasingly complex and ever-more accessible (via the ICTs) stock of knowledge. The cultural capital required to engage effectively - to be a member of 'a world of clever people'-is likely to be just as fluid and dynamic as globalisation is itself.

Therefore, education's task is to identify the curricula required for the global citzenship and to stay abreast of it continuously. Daryl Nation and I have made the following observation in this regard

Giddens's claim that globalisation necessitates a world populated by

'clever people' refers to a global population which is able to read, 
understand, analyse and, where appropriate, act knowledgeably on the information they can obtain and, indeed require, 'to engage with the wider world'. Not only does this say something about the need for high levels of education for the population, but it implies that the curricula involved need to reflect both global and local needs. We can also infer that, due to the reflexive, and therefore dynamic, nature of globalisation, people need to engage in lifelong education in order to participate fully in social life. The importance of opening education to this challenge may be self-evident...(Evans \& Nation, 1996 p.164)

This suggests that, beyond school and perhaps one's first degree, not only will lifelong education be required, but that it is likely to make extensive use of the ICTs in the form of educational technologies. Distance education, incorporating ICTs, is likely to become the norm in such lifelong education. The ICTs will be used, not only in terms of educational media, but also in terms of connecting globally to learning resources and communities. However, this does seem to require that everyone has sufficient capacity to learn in English as the global language. Of course, this raises its own problems of linguistic and cultural invasion of the local. However, the 'clever' use of global forms of education will need to involve a critical understanding of the linguistic and cultural matters that will make or break whether learning is appropriate, culturally sensitive, useful and relevant.

It can be argued that some educational institutions can (do?) behave rather like their 'rapacious' capitalist cousins and use ICTs (and other media) to 'invade' other nations and cultures and impose their own knowledge, values and ideas. (Can Universitas 21 (2002) and the Global University Alliance (2002) be seen, at least partly, in this light?) Likewise entrepreneurs have moved into the field with a view to profiting from ICT-based transnational (if not global) education. (See, for example, Blackboard (2002); NextEd (2002), Pearson (2002); Thomson Learning (2002) and WebCT (2002).) In contrast, I have argued elsewhere (Evans, 1997) that these ICTs can be (are?) used just as readily to provide 'access' to knowledge, values and ideas that empower local people to participate knowledgeably in developing their nations and societies, and to participate as global citizens. (Perhaps, the Virtual Colombo Plan (2002) will prove to be one such example.) This suggest that the purposes of educators and educational providers are important influences on the outcomes of globalising educational practices. If the purpose is profit, and it is done at the expense of damage to the local 'cultural environment', then the current gulf between the rich and poor will be widened. If its purpose is to provide access to globally relevant education that nurtures the local cultural environment, then the outcome may be to reduce the gap between rich and poor, and to lead to a sustainable existence for all. 
There are many problems that are faced by educators in the developed world who wish to work using ICTs in ways that, in effect, 'create a better world'. What follows are three brief discussions of some possible lines of research that may lead in this direction. They are intended to open possibilities for thinking about the implications of globalisation and ICTs on the future of teaching and research.

\section{WHAT IS THE PLACE OF ICTS IN RESEARCH WORK?}

To the extent that ICTs enable people and organizations to be able to communicate synchronously or asynchronously almost irrespective of location or distance (timezones notwithstanding), and they enable the storage and transmission of, or access to, considerable volumes of information and services, then ICTs have enormous potential to affect research. It seems that, in itself, this is a researchable matter. That is, in what ways have the ICTs changed the practices, nature and topics of research? For example, what sorts of research might have been undertaken if the ICTs had not existed? Or what sorts of research would not have been undertaken if the ICTs had not existed? The answers are likely to be more complex than understanding what the ICTs enable that previous communications means did not. This is because, arguably, the ICTs have markedly altered the world that needs to be/is being researched, in social, political, economic, military and cultural respects. Therefore, there are topics in each of these areas and others such as medicine, engineering, archaeology etc, that are either directly or indirectly affected

However, the ICTs have also elbowed their way on to the agenda, budgets and priorities of academies, government and research agencies. Therefore, simply to the extent that they now occupy part of the research space and they consume its resources they have the effect, as does any new field, of competing for the finite resources available for research and scholarship. A good way of reflecting on this question is to wonder what would all the professors of IT have done if they had not assumed such positions? Would they have been professors in other areas and what would this have meant? Or would they have not entered academic life at all, in which case, what would this have meant? This form of consideration could be extended to the other key areas in which the ICTs have attracted resources and attention to its research and scholarly issues.

Given the new consumption of research resources in the ICTs, the issue is raised of the extent to which old and traditional areas of scholarship have been neglected or allowed to decline as a result. What do we not know that 
we might have known about these areas? What courses and scholarship have been squeezed out to enable ICTs to be researched and studied? Of course, it is unlikely that the 'squeezing' has been done in a direct sense, that is, moving resources from a particular area of study to an area focused on an aspect of ICT. However, the 'rational' processes of contemporary government and institutional administration do favour those areas that can demonstrate some economic or industrial utility, and the ICTs have been 'blessed' with an almost religious faith in their worth in the past decade or more.

In one of the fields in which I have undertaken much of my own teaching and research over the past twenty years, distance education, there has been an enormous impact from the ICTs. For many obvious reasons, distance education has always been substantially about teaching with media that enable teachers and students to be remote from each other in time and space. The lure of the ICTs is, therefore, almost axiomatic for distance education. Even in developing nations where resources and infrastructure are often limited, the imperative to use ICTs in distance education is strong (see, Evans 2001; Jegede, 2000). A review of the conference proceedings and journal contents pages in the field over the past decade illustrates the emergence and now dominance of ICTs in the research, scholarship and practice of the field of distance education. Of course, there are also other fields of education and their journals that have also been so influenced and there are now fields and their journals that specialise in some aspect of the ICTs and education. The net effect is a major shift in research emphasis and it raises the question of what has been omitted in order to devote so much attention to ICT-related topics. Within distance education it seems evident that some of the new areas of research are being contributed by newcomers to the field. Whilst this invigoration is welcome, it has the apparent negative consequence that some well-theorised and well-researched topics in distance education are being repeated in ICT contexts in ignorance of what has been done previously. Therefore, it seems some 'reinventing of the wheel' is being undertaken (for example, in the areas of student-teacher interaction, student retention and media comparability).

This suggests that research in the ICTs needs to pay due regard to the related literature so that the new research can build on it, rather than unknowingly replicate it. It also suggests that we need to be careful in setting our research agendas so that we do not pursue research in the ICTs at the expense of other areas of research in education that are at least equally as important. 


\section{THE CHALLENGE OF GLOBALLY INCLUSIVE QUALITY EDUCATION AT A DISTANCE}

Notwithstanding the previous argument, there are important research questions and areas that need to be explored by those whose interests in the ICTs in education are ones of concern for the broader implications of the use of ICTs. As noted above, for distance educators who seek to embrace the world using the ICTs, there arises the matter of the 'access versus invasion' dilemma (Evans, 1997) that their practices bring. That is, the access to their courses by those around the world may well be seen as a benefit, especially for those who otherwise would not have had access (a major imperative of distance education for the past century at least), but the cultural invasion that comes as a consequence is something that needs to be understood. However, although research on the invasive impacts is important-and there is a good deal of research required here, given the diversity of cultural contexts that are invaded - it is what to do to minimise the consequences and, arguably, to ensure that the local is valued and developed that are the difficult research issues.

The research questions and the approaches to answering them are potentially enormous. Perhaps a fundamental question is: can a quality education be provided at a distance across national and cultural contexts? If so, then various subsidiary questions emerge such as: What constitutes quality in cross-cultural contexts? Who decides and verifies such? If quality educational transactions occur across some nations/cultures, does it imply they can occur across others/all? For example, if quality educational transactions occur between the UK and Australia in the humanities, does it mean that they can also occur between New Zealand and Germany in physical sciences, or between Israel and Iran in commerce, or between China and Samoa in social sciences?

Perhaps this book might stimulate international collaborationresearching (and developing) within its own diversities-to contribute to understanding the ways in which global diversities can be addressed. Teaching and learning approaches need to be developed and explored both with and through the ICTs to see how 'open' learning can be constructed (and reconstructed) in diverse contexts. The importance of both recognising and exploiting the reflexivity of social life - to draw on Giddens again-and the part that education plays within this appears to be one way forward to construct globally inclusive curricula. Daryl Nation and I (2001) have suggested that a form of educational 'hybridisation' occurs when an 'imported' educational element mutates into a local educational product in much the same way that a hybrid species mutates and evolves through its 
biological 'natural selection' process ('reflexiveness') within its environment. We argued that 'the reflexiveness of educational endeavours is embodied, not only in the ways in which curricula, teaching and assessment are modified and adapted to suit local circumstances and conditions, but also in the ways the people (tutors, students, etc) 'live out' these educational practices in their and their communities' own interests' (Evans \& Nation, 2001, p. 253).

The matter of English - as the global language providing access, and as the invading language trampling over local languages-is arguably one of the most researchable areas of both globalisation and globally inclusive curricula, but also one of the most problematic areas to address in practice. For example, if access to global education is mediated through English, how do we ensure that people have sufficient capacities in English to have effective access? Can the ICTs help to teach English (maybe within/alongside another curriculum area)? Can they provide sufficient 'auto-translation' to help people learn bi-lingually (that is through English and their local language)? What would it mean for education if all the citizens of the world were competent in English?

If we look at the invasive aspects, then we can commence with reframing the previous question as: What would it mean for local languages and cultures if all the citizens of the world were competent in English? What would be the consequences be for local education provision when operating alongside global education provision? Would reflexiveness suggest a need for forms of partnership between global providers and local providers? What are the consequences for people of global education on their sense of place, belonging and identity? Can the ICTs be used to facilitate inclusiveness, both linguistically and culturally?

\section{ICTS DECENTRING THE RESEARCH CENTRE.}

At this point it is worth closing with a brief consideration of some research questions on the impact of ICTs on the ways research is conducted. Contemporary research management generally favours research being conducted in areas of research strength on topics that are acknowledged priorities (as noted above, usually under some 'rational', utilitarian rubric). The research 'centre' has typically been the favoured form of intellectual and resource concentration. Such centres are located in places, they are physical entities in which researchers go about their business. The impact of the ICTs on this locational view of the research centre is worthy of research itself. The extent to which research centres are now rather more like nodes in a global 
resource concentration. Such centres are located in places, they are physical entities in which researchers go about their business. The impact of the ICTs on this locational view of the research centre is worthy of research itself. The extent to which research centres are now rather more like nodes in a global network of similar research nodes facilitated through the ICTs is worthy of research. Certainly, Jacob and Hellström (2000, p. 142) see this as an important feature of the future of research organization. The consequences of what might be called the 'decentring' of research and the networking of researchers internationally, if not globally, on the conduct of research and its dissemination are potentially major researchable topics. Likewise, as are the implications of decentring/networking for the topics of research and the nature of knowledge production. Perhaps it is possible that local research issues and knowledge production will be subsumed under layers of networked research communities working on problems that are defined as global priorities for global economic and other interests. Maybe (unwittingly?) we could well be constructing such research agendas here at this conference and neglecting our local research needs?

It is clear that for many of us in national and international research communities there are great advantages from the ICTs for the ways that we can undertake our research and scholarship. However, we need to consider the absences created by the presences of ICTs in educational (and business) practices. It may be we can live happily with the absences, but maybe there are some that, on reflection, we need to prevent. For example, most of us still value the face-to-face encounters with our colleagues, as was evident from the many conferences we hold, such as those mentioned at the beginning of this chapter. So far, the ICTs have not replaced these meetings in places. However, what does this mean for the future of research communities, will our conferences disappear? I think not because for most people they represent 'quality' encounters, that is, they find them not only useful, but pleasurable.

The notion of a 'quality encounter' also relates most strongly to teaching and learning, not just for research. The local, face-to-face educational seminar or class will remain a highly prized quality educational experience-this is not to pretend that they are all of quality and prized. Peters (2000) has suggested that the university of the future can become a seat of independent learning if it carefully and selectively fuses the media of distance education with those of on-campus life. The same may be said of quality global education, it needs to strive for ways of carefully and selectively fusing its global and local forms of education to ensure that it provides a quality experience where it matters: here and there. 


\section{REFERENCES}

Axford, B (1995). The Global System: economics, politics and culture. Cambridge, Polity Press.

Blackboard (2002) Blackboard home page http://www.blackboard.com

Bourdieu, P (1971). Intellectual field and creative project. In Young, M F D (Ed.) Knowledge and Control: new directions for the sociology of education. London, Collier-Macmillan; 161-168.

Crystal, D. (1997a) The Cambridge Encyclopedia of the English Language Cambridge: Cambridge University Press.

Crystal, D. (1997b) English as a Global Language Cambridge: Cambridge University Press.

Cunningham, S. \& others (1998) New Media and Borderless Education: a review of the convergence between global media networks and higher education provision Canberra, Australian Government Publishing Service.

Cunningham, S. \& others (2000) The Business of Borderless Education Canberra, Department of Education and Youth Affairs.

Evans, T. D. (1997). (En)Countering globalisation: issues for open and distance educators' In Rowan, L, Bartlett, L \& Evans, T D (Eds) Shifting Borders: globalisation, localisation and open and distance education. Geelong, Deakin University Press; 11-22.

Evans, T. D. (2001). Policy and planning in the developed countries: coping with compulsive development cultures.. In S. Panda (Ed.) Planning and Management of Open and Flexible Learning. London, Kogan Page; 13-19.

Evans, T. D. (2002). Distance education, technology, interaction and globalisation keynote paper presented at the I Congresso Brasileiro de Ensino Superior a Distância- "Educação a Distância no Ensino Superior ` Qualidade e Eficácia, Petropolis, Brazil, March, 2002 (in press, Portuguese).

Evans, T. D. (2002b). Keynote presentation on A brief review of undergraduate distance education: an Australian perspective at the I Congresso Brasileiro de Ensino Superior a Distância- "Educação a Distância no Ensino Superior ` Qualidade e Eficácia, Petropolis, Brazil, March, 2002.

Evans, T. D. \& Nation, D. E. (2001). The interrelationships between globalisation and open and distance education. Indian Journal Of Open Learning 10 (3): 241-258.

Evans, T. D. \& Stacey, E. (2002). Flexible learning for quality in higher education. Keynote paper presented at EDU-COM 2002 Conference, Higher Education Without Borders: sustainable development in higher education. Khon Kaen, Thailand, 25-27 November, 2002.

Giddens, A (1991a). The Consequences of Modernity. Cambridge, Polity Press.

Giddens, A (1991b). Modernity and Self-Identity: self and society in the late modern age. Cambridge, Polity Press.

Giddens, A. (1994). Beyond Left and Right: the future of radical politics. Cambridge: Polity Press.

Global University Alliance (2002) Global University Alliance home page http://www.gua.com .

Jacob, M \& Hellström, T, (Eds) (2000). The Future of Knowedge Production in the Academy. Buckingham, SHRE and the Open University Press.

Jegede, O. (2000). The wedlock between technology and open and distance education. In Evans, T. D. \& Nation, D. E. (Eds) Changing University Teaching: reflections on creating educational technologies. London, Kogan Page; 45-55.

NextEd (2001). NextEd home page http://www.nexted.com last accessed 15 August 2001.

Pearson Education (2002) Pearson Education home page http://www.pearson-education.com. 
Peters, O. (2000). The transformation of the university into an institution of independent learning. In Evans, T. D. \& Nation, D. E. (Eds) Changing University Teaching: reflections on creating educational technologies. London, Kogan Page; 10-23.

Thomson Learning (2002). Thomson Learning home page http://www.thomsonlearning.com

Universitas 21 (2002). Universitas 21 home page http://www.universitas.edu.au.

Virtual Colombo Plan, (2002). http://www.ausaid.gov.au/hottopics/

WebCT (2002). WebCT home page http://www.webct.com 